Jpn. J. Infect. Dis., 73, 205-209, 2020

Original Article

\title{
Effect of High Blood Glucose Level on the Antimicrobial Activity of Daptomycin against Staphylococcus aureus in Streptozotocin-Induced Diabetic Mice
}

\author{
Takayuki Kondo ${ }^{1}$, Mao Hagihara ${ }^{1,2}$, Yukihiro Esaka ${ }^{3}$, Takuhei Yamamoto ${ }^{3}$, Bunji Uno ${ }^{3}$, \\ Yuka Yamagishi ${ }^{1}$, and Hiroshige Mikamo ${ }^{1 *}$ \\ ${ }^{I}$ Department of Clinical Infectious Diseases, Aichi Medical University Graduate School of Medicine; \\ ${ }^{2}$ Department of Molecular Epidemiology and Biomedical Sciences, Aichi Medical University, Aichi; and \\ ${ }^{3}$ Gifu Pharmaceutical University, Gifu, Japan
}

\begin{abstract}
SUMMARY: Daptomycin is active against Staphylococcus aureus including methicillin-resistant S. aureus (MRSA), demonstrating efficacy in the treatment of infections in diabetic patients. However, daptomycin degrades in 5\% glucose solution, and data on the efficacy of daptomycin in hyperglycemic patients are limited. Therefore, we investigated the effect of high levels of blood glucose on the efficacy and concentration of daptomycin. The efficacy of simulated human exposure to daptomycin against $S$. aureus was compared in a neutropenic murine thigh model, with and without hyperglycemia. A clinically isolated MRSA strain and S. aureus ATCC25923 standard strain were used. Daptomycin concentrations, in the serum and at the infected site, were preliminarily analyzed using the high-performance liquid chromatography assay. Even in hyperglycemic mice, the mean concentration of daptomycin in hyperglycemic mice was equivalent to that in untreated mice within the physiological blood glucose levels. Additionally, the efficacy of daptomycin against MRSA was equal to that observed in the untreated and hyperglycemic mice. Based on similar studies using $S$. aureus ATCC25923, the efficacy in hyperglycemic mice was equal to or greater than that observed in untreated mice. In conclusion, daptomycin is an alternative therapeutic option in diabetic mice with serious staphylococcal infections, regardless of blood glucose control in this animal model.
\end{abstract}

\section{INTRODUCTION}

Patients with diabetes mellitus (DM) demonstrate higher rates of impaired immunity compared to nondiabetic subjects (1). Several studies have suggested a positive association between diabetes and the development of several types of infections (2-4). Based on a survey, the principal cause of death among Japanese patients with diabetes indicated that infections were the third leading cause of death (5). More patients with DM had a fatal outcome due to Staphylococcus aureus and methicillin-resistant $S$. aureus (MRSA) infections compared to non-diabetes patients (6). Notably, MRSA remains highly prevalent in Japanese hospitals. Furthermore, while MRSA infections have been decreasing over the last decade, the speed of decline appears to have slowed down post-2013, with 2016 rates at 311 per 100,000 hospitalized patients (7).

Daptomycin (DAP) is active against $S$. aureus,

Received November 9, 2019. Accepted December 2, 2019. J-STAGE Advance Publication December 25, 2019.

DOI: 10.7883 /yoken.JJID.2019.457

*Corresponding author: Mailing address: Department of Clinical Infectious Diseases, Aichi Medical University Graduate School of Medicine, 1-1, Yazakokarimata, Nagakute, Aichi 480-1195, Japan. Tel: +81-561-62-3311, Fax: +81-561-61-1842, E-mail: mikamo@aichi-med-u.ac.jp including MRSA (8). Several studies have suggested the clinical utility of DAP in diabetic patients $(6,9-13)$. However, DAP undergoes $15-20 \%$ degradation in $5 \%$ glucose solution in $24 \mathrm{~h}$ at room temperature by glycosylation (14). Moreover, these investigations failed to report patient blood glucose levels $(6,9-13)$. Hence, the effect of high-level blood glucose on the efficacy of DAP has not been evaluated, and no evidence on DAP efficacy in diabetic patients with hyperglycemia is currently available. Therefore, we investigated the efficacy and concentration of DAP in hyperglycemic mice (referred to as DM mice in this study) and compared the efficacy of DAP with Linezolid (LZD), which is stable in a glucose solution and penetrates well into the tissue in diabetes patients $(15,16)$.

\section{MATERIALS AND METHODS}

Antimicrobial agents and dose setting: DAP for injection (Lot: S015115, MSD, Inc., Tokyo, Japan) was used throughout this study. Immediately prior to each experiment, DAP powder was diluted in $0.9 \%$ saline based on the mean animal weight to achieve the desired concentration. LZD for injection (Lot: 18K07U08, Pfizer, Inc., Tokyo, Japan) was used. The solutions of each antibiotic were freshly prepared at the beginning of each study.

The dose of DAP and LZD was $43 \mathrm{mg} / \mathrm{kg}$ daily and $120 \mathrm{mg} / \mathrm{kg}$ twice daily, respectively. This was determined to assess the in vivo activity of simulated 
human DAP (6 mg/kg daily) and LZD (600 mg twice daily) against MRSA in accordance with previous studies $(17,18)$ and were administered subcutaneously.

Microorganisms: The $S$. aureus ATCC 25923 standard strain and a clinical strain of MRSA (AMU-1) collected from a patient at the Aichi Medical University Hospital (Aichi, Japan) were used in this study. For each experiment, the strains were cultured overnight on Trypticase Soy Agar (TSA) plates with 5\% sheep blood (Becton, Dickinson \& Co., Sparks, MD, USA) to confirm their purity and viability. As reported previously, the minimum inhibitory concentration (MIC) of DAP and LZD for ATCC25923 was $0.25 \mu \mathrm{g} / \mathrm{mL}$ and $1 \mu \mathrm{g} / \mathrm{mL}$, respectively $(19,20)$. The MIC of DAP for AMU-1 was $0.5 \mu \mathrm{g} / \mathrm{mL}(17)$.

Animals: Four-week-old, female, specific pathogenfree ICR Swiss mice (weighing approximately 18 to 24 g) were purchased (Charles River Laboratories Japan, Inc. Yokohama, Japan), and were maintained and used in accordance with the National Research Council recommendations with food and water provided ad libitum. The study was reviewed and approved by the Aichi Medical University Hospital' Institutional Animal Care and Use Committee.

Induction of diabetes: The streptozotocin (STZ)induced diabetes model was adopted in this study as previously described (21). Mice were fasted for $4 \mathrm{~h}$ before the STZ administration and then administered a single intraperitoneal injection of freshly prepared 200 $\mathrm{mg} / \mathrm{kg} \mathrm{STZ} \mathrm{(Sigma-Aldrich,} \mathrm{Tokyo,} \mathrm{Japan).} \mathrm{Untreated}$ mice were injected with an equivalent volume of $0.9 \%$ saline. Blood glucose levels were monitored using a blood glucose meter with a tail-vein blood sample (Glucose Pilot $^{\circledR}$, Technicon International, Inc., Tokyo, Japan). After 1 week of STZ administration, mice were considered DM mice (blood glucose level $>400 \mathrm{mg}$ / dL).

Neutropenic murine thigh infection model: As previously described (22), mice were rendered neutropenic following the intraperitoneal administration of cyclophosphamide (Sigma-Aldrich) at 150 and 100 $\mathrm{mg} / \mathrm{kg}$ of the body weight, 4 days and 1 day prior to inoculation, respectively.

Two transfers of the organism were performed onto TSA plates with $5 \%$ sheep blood, and the plates incubated at $37^{\circ} \mathrm{C}$. After an $18-24 \mathrm{~h}$ incubation for the second transfer, a bacterial suspension was prepared for inoculation. Each murine thigh was inoculated intramuscularly with $0.1 \mathrm{~mL}$ solution containing approximately $1 \times 10^{6}$ to $1 \times 10^{7} \mathrm{CFU} /$ tissue of the test isolate (0.5-1 McFarland standard), and the antimicrobial therapy was initiated $2 \mathrm{~h}$ later.

In vivo efficacy assessed by bacterial density: The concentration of the bacterial inoculum was confirmed by quantitative culture. After 1 and $24 \mathrm{~h}$ of initial antimicrobial administration, the mice were sacrificed by $\mathrm{CO}_{2}$ asphyxiation. The thighs were immediately removed and homogenized in $0.9 \%$ sterile iced saline. Serial dilutions of the thigh homogenate were subcultured onto TSA plates with $5 \%$ sheep blood to determine bacterial density. Efficacy defined as a change in bacterial density and was calculated as the difference in the $\log _{10} \mathrm{CFU} /$ tissue between the treated and control mice at the respective time points.
High-performance liquid chromatographic (HPLC) analysis of DAP: A Model 10AD VP HPLC system (Shimadzu, Kyoto, Japan) equipped with a DGU-12A degasser (Shimadzu), a CLASS M10A (SPDMXA) photodiode array detector (Shimadzu), and a Model 7125 syringe-loading sample injector (Rheodyne, Cotati, CA, USA) was used. HPLC separations were performed on an Inertsil ${ }^{\circledR}$ ODS-3 $(150 \times 4.6 \mathrm{~mm}$ i.d., $5 \mu \mathrm{m}$ particle size) column (GL Sciences Inc., Tokyo, Japan) with a mobile phase of $0.01 \mathrm{~mol} / \mathrm{L}$ phosphate buffer ( $\mathrm{pH} 2.1$ ) containing $36 \%$ acetonitrile at a flow rate of $1.0 \mathrm{~mL} / \mathrm{min}$ at $40^{\circ} \mathrm{C}$. The column effluent was monitored at $221 \mathrm{~nm}$, and peak analyses were performed using a Class M10A system (Shimadzu). Analytical grade 4-nitrophenol was commercially available from Kishida Chemical Co., Ltd. (Osaka, Japan) and was used without further purification as an internal standard for the HPLC analysis of DAP. HPLC-grade acetonitrile as an HPLC eluent was used as received without further purification.

Quantification of DAP in murine serum samples: The procedure for DAP quantification in murine serum was as previously described (13). Briefly, to deproteinize the serum, a mixture of a $400 \mu \mathrm{L}$ serum sample and $0.8 \mathrm{~mL}$ acetonitrile was vortexed and centrifuged at $15,500 \times g$ for $15 \mathrm{~min}$. The supernatant $(600 \mu \mathrm{L})$ was aspirated using a micropipette, followed by evaporation to dryness using a centrifuge evaporator. The residue, dissolved in $200 \mu \mathrm{L}$ of water containing 4-nitrophenol as an internal standard, was applied to an Ultrafree-MC $(0.22 \mu \mathrm{m}$ pore size $)$ centrifuge filter available from Merck Millipore using a centrifuge set at $6,000 \times g$ at $4^{\circ} \mathrm{C}$ for $10 \mathrm{~min}$. A $20-\mu \mathrm{L}$ aliquot of the filtrate was injected into the HPLC apparatus.

A calibration curve to determine DAP in the serum samples was generated by plotting the peak height ratios of DAP relative to the internal standard against the concentrations in spiked serum standards. These were prepared by spiking drug-free mouse serum $(360 \mu \mathrm{L})$ with a $40 \mu \mathrm{L}$ aliquot of DAP standard solution prepared at various concentrations by diluting the $100 \mu \mathrm{mol} / \mathrm{L}$ aqueous solution of DAP. The limit of detection, defined as the lowest concentration that gives a signal-to-noise ratio of at least 3 , was found to be $0.8 \mu \mathrm{mol} / \mathrm{L}$ for DAP. The linear relation spanning the $1.0-10.0 \mu \mathrm{M}$ range was obtained $(r=0.992)$ and was validated by evaluating reproducibility and recovery using three concentrations of DAP: $1 \mu \mathrm{mol} / \mathrm{L}$ (low level), $5 \mu \mathrm{mol} / \mathrm{L}$ (medium level), and $10 \mu \mathrm{mol} / \mathrm{L}$ (high-level). The reproducibility for six repeated experiments were $12.3,5.2$, and $1.5 \%$ for the low, medium, and high concentration levels, respectively. The mean recovery values for six trials were 95.2, 98.5, and 99.2\% for the low, medium, and high concentration levels, respectively.

Quantification of DAP in murine thigh muscle samples: Recently, we developed a sample preparation method to efficiently quantify DAP in murine thigh muscles (23). Trypsin-EDTA solution without phenol red $(150 \mu \mathrm{L})$,(Fujifilm Wako Pure Chemical Co., Osaka, Japan), and $0.1 \mathrm{~mol} / \mathrm{L}$ Tris-HCl buffer $(\mathrm{pH} \mathrm{8)}$ solution $(200 \mu \mathrm{L})$ were added to a tube $(2 \mathrm{~mL})$ containing the accurately weighed muscle homogenate, which was then sealed with a cap and incubated at $37^{\circ} \mathrm{C}$ for $30 \mathrm{~min}$. The contents of the tube were vortexed to 
yield a homogeneous suspension, followed by further mixing on a vortex mixer for 10 min after the addition of methanol $(600 \mu \mathrm{L})$ and chloroform $(300 \mu \mathrm{L})$. Subsequently, the contents of the tube were vortex mixed with $300 \mu \mathrm{L}$ chloroform and $400 \mu \mathrm{L}$ water for $30 \mathrm{~s}$ and were centrifuged at $3,000 \times g$ for $5 \mathrm{~min}$ to extract DAP into the aqueous phase. The supernatant $(1.0 \mathrm{~mL})$ was aspirated using a pipette, followed by evaporation to dryness using an evaporator. The residue was dissolved in $50 \mu \mathrm{L}$ of water containing the internal standard and applied to an Ultrafree-MC $(0.22 \mu \mathrm{m}$ pore size) filter using a centrifuge set at $6,000 \times g$ at $4^{\circ} \mathrm{C}$ for $10 \mathrm{~min}$. Next, a $20 \mu \mathrm{L}$ aliquot of the filtrate was injected onto the HPLC column. The calibration curve and method validation were performed as previously described (23).

Statistical analysis: The efficacy was examined for each strain as mean changes in bacterial numbers obtained from the control $(0 \mathrm{~h})$ and treated mice after 1 and $24 \mathrm{~h}$. An analysis of variance (ANOVA) model, including the conditions of the mouse group, time, and the interaction of mice type and time was used to compare and estimate the differences between the two mouse groups at each time. Mean glucose at baseline in each strain and mean DAP concentration in the serum or thigh were compared between the two mouse groups using a two-sample $t$-test (Satterthwaite). A similar ANOVA model as above, including the conditions of the mouse group, time and the interaction of mouse group and time were performed to compare the two mouse groups and to compare DAP and LZD at each time point. A $p$-value of 0.05 or less was defined as statistically significant.

\section{RESULTS}

Changes in blood glucose levels induced by STZ: Following STZ administration, the mice were provided with food and water ad libitum. Compared to the untreated mice, the mean blood glucose levels of observed in DM mice were significantly higher (ATCC25923, untreated $232.2 \pm 14.6 \mathrm{mg} / \mathrm{dL}$ vs. DM $457.3 \pm 41.1 \mathrm{mg} / \mathrm{dL} ;$ AMU-1, untreated $190.2 \pm 8.54$ vs. $\mathrm{DM} 502.5 \pm 42.6, P<0.001)$.

In vivo efficacy of DAP: The change in $\log _{10}$ CFU/tissue for each treatment period, i.e. 1 and $24 \mathrm{~h}$ relative to $0 \mathrm{~h}$ is shown in Figs. 1 and 2. Prior to DAP administration, at $0 \mathrm{~h}$, the mean bacterial densities in the thighs of untreated mice and DM mice ranged from 6.76 to $7.31 \log _{10} \mathrm{CFU} /$ tissue and 6.87 to $7.12 \log _{10} \mathrm{CFU} /$ tissue, respectively. After $24 \mathrm{~h}$, the isolates grew to 7.70 to $8.83 \log _{10} \mathrm{CFU} /$ tissue and 8.17 to $9.11 \log _{10} \mathrm{CFU} /$ tissue in untreated mice and DM mice, respectively.

To investigate the efficacy of DAP in hyperglycemic conditions in clinical practice, we evaluated the efficacy using AMU-1. In the infection model with AMU-1, DAP demonstrated early antimicrobial activity after $1 \mathrm{~h}$, with equal activity observed in DM mice compared to the untreated mice after $1 \mathrm{~h}$ (untreated $-1.80 \pm 0.33$ vs. $\mathrm{DM}-1.99 \pm 0.21 \log _{10} \mathrm{CFU} /$ tissue) and $24 \mathrm{~h}$ (untreated $-1.31 \pm 0.95$ vs. DM $-1.36 \pm 1.02 \log _{10}$ CFU/tissue) (Fig. $1)$.

Reportedly, LZD is stable in 5\% and $10 \%$ glucose solution for 34 days at $35^{\circ} \mathrm{C}(15)$. To compare the

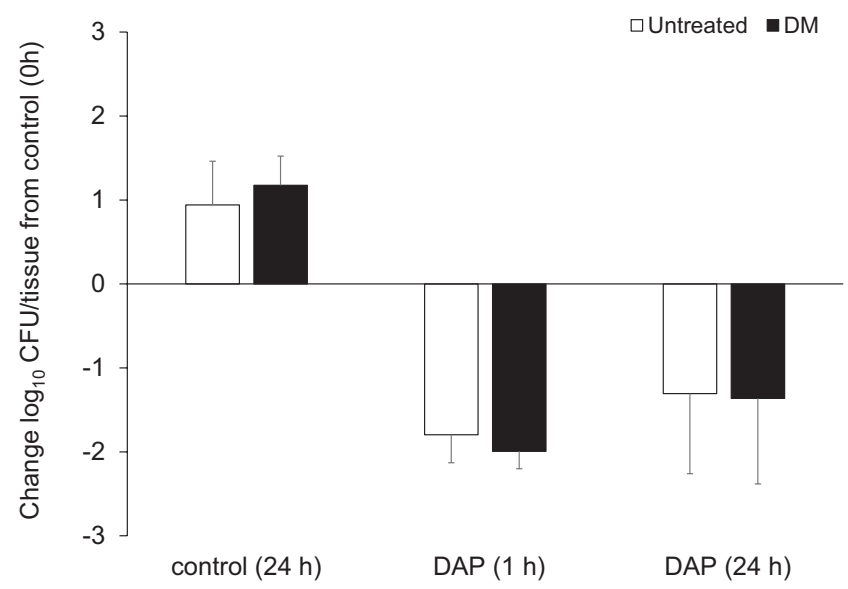

Fig. 1. Comparative efficacies of human simulated DAP regimen against AMU-1 in untreated and DM neutropenic murine thigh infection model at 1 and $24 \mathrm{~h}$. Bars represent mean \pm standard deviation for 4 to 6 infected thighs per group.

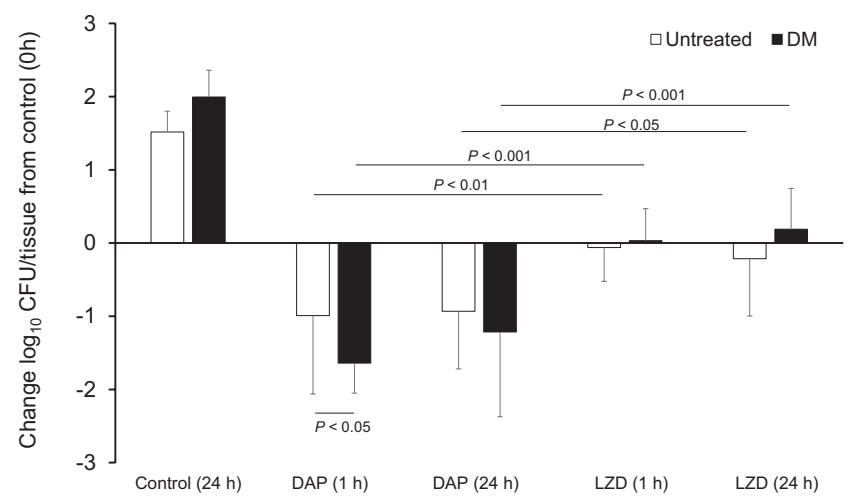

Fig. 2. Comparative efficacies of human simulated DAP and LZD regimen against ATCC25923 in untreated and DM neutropenic murine thigh infection model at 1 and $24 \mathrm{~h}$. Bars represent mean \pm standard deviation for 12 infected thighs per group.

antimicrobial activity with other drugs, we preliminarily compared the efficacies of DAP and LZD using the same infection model with ATCC25923. The change in $\log _{10} \mathrm{CFU} /$ tissue for each treatment is shown in Fig. 2. In the case of DAP, the change in $\log _{10} \mathrm{CFU} /$ tissue demonstrated the same tendency as in Fig. 1. However, a significant difference in the antimicrobial activity was observed after $1 \mathrm{~h}$ between the untreated mice and DM mice. On the other hand, between untreated mice and DM mice, no statistical differences were observed in the antimicrobial activities of LZD both after 1 and $24 \mathrm{~h}$, and the time-course of antimicrobial activities of LZD paralleled those of DAP.

DAP concentration in the serum and thigh muscle: DAP concentrations in the infected tissues and serum were measured to assess the effect of blood glucose levels on DAP efficacy (Table 1). DAP concentrations at $24 \mathrm{~h}$ after administration were not detectable or were near the lower detection limit. The mean DAP concentration in the serum of DM mice was lower than that in the untreated mice. However, no statistically significant difference was observed between the $\mathrm{DM}$ mice and untreated mice in the serum and thigh muscles. 
Table 1. DAP concentration in serum and thigh samples from untreated and diabetic mice

\begin{tabular}{|c|c|c|c|c|}
\hline & & $\begin{array}{l}\text { Untreated Mice } \\
\text { (range) }\end{array}$ & $\begin{array}{l}\text { Diabetic Mice } \\
\text { (range) }\end{array}$ & $P$-value \\
\hline \multirow[t]{2}{*}{ Serum } & $1 \mathrm{~h}$ & $\begin{array}{l}615.8 \pm 70.6 \mu \mathrm{g} / \mathrm{mL} \\
(531.2-675.7)\end{array}$ & $\begin{array}{l}518.4 \pm 114.4 \mu \mathrm{g} / \mathrm{mL} \\
(395.8-638.7)\end{array}$ & 0.32 \\
\hline & $24 \mathrm{~h}$ & Not detected $^{1)}$ & Not detected ${ }^{1)}$ & - \\
\hline \multirow[t]{2}{*}{ Thigh } & $1 \mathrm{~h}$ & $\begin{array}{l}1.29 \pm 0.50 \mu \mathrm{g} / \mathrm{g} \text { tissue } \\
(0.81-1.78)\end{array}$ & $\begin{array}{l}1.38 \pm 0.32 \mu \mathrm{g} / \mathrm{g} \text { tissue } \\
(0.99-1.70)\end{array}$ & 0.80 \\
\hline & $24 \mathrm{~h}$ & Not detected ${ }^{1)}$ & Not detected ${ }^{1)}$ & - \\
\hline
\end{tabular}

${ }^{1)}$ : DAP concentrations were not detectable or were near the lower detection limit.

\section{DISCUSSION}

To our knowledge, the present study is the first to evaluate the relationship between blood glucose levels and the efficacy and concentration of DAP using a murine thigh infection model. Our study showed that even in hyperglycemic mice, DAP revealed rapid tissue penetration and efficacy against $S$. aureus, including MRSA. Furthermore, this efficacy was equal to or greater than that observed in the untreated mice with physiological blood glucose levels. Our results suggest that DAP could be effective in $S$. aureus infections in diabetic patients. Previously, the clinical success rates for DAP against $S$. aureus bacteremia and in infective endocarditis patients with and without DM were similar at $68.2 \%$ and $71.1 \%$, respectively. Furthermore, regarding the mortality rate by organism, the mortality in diabetes patients was higher in the MRSA group than in the MSSA group, and in the DM group than in the non-diabetic group (non-diabetes patients with MSSA; $8.4 \%$, diabetes patients with MSSA; $15.7 \%$, nondiabetes patients with MRSA; $16.7 \%$, diabetes patients with MRSA; $31.4 \%$ ) (6). However, this report failed to include relevant information on the blood glucose levels in the patient history. Hence, the utility of DAP in hyperglycemic patients has not been clarified. Our results in the murine model are consistent with the results of this previous report and provide new findings regarding DAP in a hyperglycemic situation.

Moreover, it has been suggested that DAP could be a therapeutic alternative to LZD in patients with diabetes demonstrating serious staphylococcal infections irrespective of blood glucose control. DAP binds to the bacterial membrane and causes rapid depolarization of the membranes, thereby exhibiting rapid bactericidal activity, while LZD exerts its bacteriostatic effect by inhibiting protein synthesis. The significant difference in the bacterial density between DAP and LZD may be attributed to the difference in the mechanism of action.

Additionally, equivalent or superior efficacy of DAP in DM mice was observed compared to that in untreated mice. This suggested the possibility that DAP has higher efficacy in hyperglycemic patients compared to nondiabetic patients. Prax et al. discuss two hypotheses for the mechanism of the glucose-DAP effect, the influence of the glucose transport proteins on the DAP mode of action, and the glucose-induced and DAP-specific lysis of cells. This enhancement effect of glucose was not observed with penicillin and vancomycin (24). This effect on DAP antimicrobial activity could explain the increased efficacy observed in the DM mice. However, the reason for the greater bacterial reduction observed in ATCC25923 than that in MRSA remains unknown. Potentially, DAP induced killing by glucose addition may be more enhanced in S. aureus than that in MRSA.

Lastly, our study suggests the possibility that blood glucose has almost no effect on the efficacy and concentration of DAP. In our results, the DAP concentrations in sera and the thigh muscle of DM mice did not differ from those in untreated mice $1 \mathrm{~h}$ after administration. Moreover, in the results for DAPsusceptible strains, no reduction in the efficacy of DAP by blood glucose was observed until $24 \mathrm{~h}$ after DAP administration. Saint Paul et al. evaluated the stability of DAP in peritoneal dialysis solutions containing 1.36 $\mathrm{w} / \mathrm{v} \%$ glucose and reported that $102 \%$ of the initial concentration remained after $6 \mathrm{~h}$ at $37^{\circ} \mathrm{C}(25)$. In our study, the mean blood glucose level in DM mice was approximately $500 \mathrm{mg} / \mathrm{dL}$, which amounts to $0.5 \mathrm{w} / \mathrm{v} \%$. This was lower than that reported previously, and our result for the DAP concentration was consistent with the result of this report (25).

There are several limitations to this study. First, we failed to investigate the effect of blood glucose on DAP at $24 \mathrm{~h}$ after administration as the concentration of DAP in the serum and thigh muscle were below the detection limit or near the lower detection limit. Previously, the stability of DAP in peritoneal dialysis solution containing $1.36 \mathrm{w} / \mathrm{v} \%$ glucose remained $74 \%$ after 24 $\mathrm{h}$ at $37^{\circ} \mathrm{C}(25)$. Thus, we cannot deny the possibility that DAP was degraded by blood glucose at $24 \mathrm{~h}$ after administration. Second, there was a limitation in the detection sensitivity for measuring DAP concentration. The elimination half-life $\left(t_{1 / 2}\right)$ of DAP differs between humans and rodents, and the $\mathrm{t}_{1 / 2}$ of DAP in mice was shorter than that in humans $(1.4 \mathrm{~h}$ vs. $8.1-9 \mathrm{~h})$ $(17,26)$. Therefore, it has been reported that the DAP concentration in rodents fell below the detection limit by 9 or $12 \mathrm{~h}$ after administration (17,27). Third, this study only used two $S$. aureus strains. Further clinical research is thus needed to determine the utility of DAP in diabetic patients.

In conclusion, DAP is effective and an alternative therapeutic option in diabetic mice with serious staphylococcal infections irrespective of blood glucose control. 
Conflict of interest T. Kondo is an employee of MSD.K.K., which produces a product within MRSA area. MSD.K.K. had no role in the design, execution, analysis, and interpretation of this study.

\section{REFERENCES}

1. Geerlings SE, Hoepelman AI. Immune dysfunction in patients with diabetes mellitus (DM). FEMS Immunol Med Microbiol. 1999;26:259-65.

2. Muller LM, Gorter KJ, Hak E, et al. Increased risk of common infections in patients with type 1 and type 2 diabetes mellitus. Clin Infect Dis. 2005;41:281-8.

3. Shah BR, Hux JE. Quantifying the risk of infectious diseases for people with diabetes. Diabetes Care. 2003;26:510-3.

4. Abu-Ashour W, Twells L, Valcour J, et al. The association between diabetes mellitus and incident infections: a systematic review and meta-analysis of observational studies. BMJ Open Diabetes Res Care. 2017;5(1):e000336.

5. Hotta N, Nakamura J, Iwamoto Y, et al. Causes of death in Japanese diabetics based on the results of a survey of 18,385 diabetics during 1991- 2000. J Japan Diab Soc. 2007;50:47-61.

6. Kanafani ZA, Kourany WM, Fowler VG Jr, et al. Clinical characteristics and outcomes of diabetic patients with Staphylococcus aureus bacteremia and endocarditis. Eur J Clin Microbiol Infect Dis. 2009;28:1477-82.

7. Government of Japan. National action plan on antimicrobial resistance (AMR): 2016e2020. Tokyo: Government of Japan;2016. Available at: <http://www.mhlw.go.jp/file/06Seisakujouhou-10900000-Kenkoukyoku/0000138942.pdf> Japanese. Accessed June 10, 2019.

8. Mizuno S, Iwami M, Kunisawa S, et al. Comparison of national strategies to reduce metichillin-resistant Staphylococcus aureus infections in Japan and England. J Hosp Infect. 2018;100:280-98.

9. Schriever CA, Fernández C, Rodvold KA, et al. Daptomycin: a novel cyclic lipopeptide antimicrobial. Am J Health Syst Pharm. 2005;62:1145-58

10. Lipsky BA, Stoutenburgh U. Daptomycin for treating infected diabetic foot ulcers: evidence from a randomized, controlled trial comparing daptomycin with vancomycin or semi-synthetic penicillins for complicated skin and skin-structure infections. J Antimicrob Chemother. 2005;55:240-5.

11. Kim A, Suecof LA, Sutherland CA, et al. In vivo microdialysis study of the penetration of daptomycin into soft tissues in diabetic versus healthy volunteers. Antimicrob Agents Chemother. 2008;52:3941-6.

12. Traunmüller F, Schintler MV, Metzler J, et al. Soft tissue and bone penetration abilities of daptomycin in diabetic patients with bacterial foot infections. J Antimicrob Chemother. 2010;65:12527.

13. Cogo A, Gonzalez-Ruiz A, Pathan R, et al. Real-world treatment of complicated skin and soft tissue infections with daptomycin: results from a large European registry (EU-CORE). Infect Dis Ther. 2015;4:273-82.
14. Inman EL, Kirsch LE. Assignee: Eli Lilly and Company. An improved diluent formulation for daptomycin. European Patent Office patent EP0386951, filed 2 March 1990, issued 12 September 1990. Available at $<$ https://patentimages. storage. googleapis.com/52/47/25/1ebfd50c8bffda/EP0386951A2.pdf> Accessed 1 July 2019.

15. Taylor R, Sunderland B, Luna G, et al. Evaluation of the stability of linezolid in aqueous solution and commonly used intravenous fluids. Drug Des Devel Ther. 2017;11:2087-97.

16. Wiskirchen DE, Shepard A, Kuti JL, et al. Determination of tissue penetration and pharmacokinetics of linezolid in patients with diabetic foot infections using in vivo microdialysis. Antimicrob Agents Chemother. 2011;55:4170-5.

17. Kato H, Hagihara M, Murakami E, et al. Considerations about the use of a loading dose of daptomycin in a neutropenic murine thigh infection model with methicillin-resistant Staphylococcus aureus infection. Chemotherapy. 2018;63:13-9.

18. Tessier PR, Keel RA, Hagihara M, et al. Comparative in vivo efficacies of epithelial lining fluid exposures of tedizolid, linezolid, and vancomycin for methicillin-resistant Staphylococcus aureus in a mouse pneumonia model. Antimicrob Agents Chemother. 2012;56:2342-6.

19. Grohs P, Kitzis MD, Gutmann L. In vitro bactericidal activities of linezolid in combination with vancomycin, gentamicin, ciprofloxacin, fusidic acid, and rifampin against Staphylococcus aureus. Antimicrob Agents Chemother. 2003;47:418-20.

20. Rybak MJ, Hershberger E, Moldovan T, et al. In vitro activities of daptomycin, vancomycin, linezolid, and quinupristin-dalfopristin against staphylococci and enterococci, including vancomycinintermediate and -resistant strains. Antimicrob Agents Chemother. 2000;44:1062-6.

21. Hayashi K, Kojima R, Ito M. Strain differences in the diabetogenic activity of streptozotocin in mice. Biol Pharm Bull 2006;29:1110-9.

22. Yamagishi Y, Mikamo H, Kato H, et al. Efficacy of tedizolid against methicillin-resistant Staphylococcus aureus and Peptostreptococcus anaerobius in thigh mixed-infection mouse model. J Infect Chemother 2017;23:368-73.

23. Sakai Y, Murakami E, Kato H, et al. Feasibility of trypsin digestion as a sample preparation for daptomycin quantification in murine skeletal muscles. Biol Pharm Bull. 2019;42:751-7.

24. Prax M, Mechler L, Weidenmaier C, et al. Glucose augments killing efficiency of daptomycin challenged Staphylococcus aureus persisters. PLoS One. 2016;11:e150907.

25. Peyro-Saint-Paul L, Albessard F, Gaillard C, et al. Daptomycin compatibility in peritoneal dialysis solutions. Perit Dial Int. 2011;31:492-5.

26. Dvorchik BH, Brazier D, DeBruin MF, et al. Daptomycin pharmacokinetics and safety following administration of escalating doses once daily to healthy subjects. Antimicrob Agents Chemother. 2003;47:1318-23.

27. Matsumoto K, Kitaoka M, Kuroda Y, et al. Pharmacokinetics and skin-tissue penetration of daptomycin in rats. Clin Pharmacol. 2015;7:79-82. 